\title{
The Role of Telemedicine to Alleviate an Increasingly Burdened Healthcare System: Retinopathy of Prematurity
}

Fares Antaki · Kenan Bachour · Tyson N. Kim - Cynthia X. Qian

Received: May 13, 2020 / Published online: June 19, 2020

(C) The Author(s) 2020

\section{ABSTRACT}

Telemedicine-based remote digital fundus imaging (RDFI-TM) offers a promising platform for the screening of retinopathy of prematurity. RDFI-TM addresses some of the challenges faced by ophthalmologists in examining this vulnerable population in both low- and high-income countries. In this review, we studied the evidence on the use of RDFI-TM and analyzed the practical framework for RDFI-TM systems. We assessed the novel technological advances that can be deployed within RDFI-TM systems including noncontact imaging systems, smartphone-based imaging tools, and deep learning algorithms.

Digital Features To view digital features for this article go to https://doi.org/10.6084/m9.figshare.12465239.

F. Antaki · C. X. Qian $(\bowtie)$

Department of Ophthalmology, Centre

Universitaire d'Ophtalmologie (CUO), Hôpital

Maisonneuve-Rosemont, Université de Montréal,

Montréal, QC, Canada

e-mail: cynthia.xin-ya.qian@umontreal.ca

K. Bachour

Faculty of Medicine and Health Sciences, Université

de Sherbrooke, Sherbrooke, QC, Canada

T. N. Kim

Department of Ophthalmology, University of

California, San Francisco, San Francisco, CA, USA
Keywords: Artificial intelligence; Remote digital fundus imaging; Retinopathy of prematurity; Telemedicine

\section{Key Summary Points}

Over the last 20 years, telemedicine-based remote digital fundus imaging evaluation for ROP gradually transitioned from being a research tool to becoming a routinely used method of ROP screening alongside ophthalmoscopy.

Telemedicine has increased the accessibility of screening for ROP by complementing the screening effort in high-income countries and by overcoming geographic and resource limitations in low-income countries.

Novel noncontact digital cameras and smartphone-based imaging systems have the potential for improving image acquisition in telemedicine-based ROP screening programs.

Deep learning in ROP screening holds great promise but remains a research tool at the moment. Currently available algorithms have demonstrated capacity to accurately and consistently detect plus disease, a diagnostic classification that expert ophthalmologists frequently disagree on. 


\section{INTRODUCTION}

Retinopathy of prematurity (ROP) is a neovascular retinal disorder that occurs in low birth weight premature infants. It is a leading cause of childhood blindness in industrialized as well as developing nations [1]. In the USA, between 2000 and 2012, the incidence of ROP rose from $15 \%$ to $20 \%$ [2]. Elsewhere in the world, an increase in premature birth rates coupled with higher neonatal intensive care unit (NICU) admissions has also led to a substantial increase in the number of cases [3]. These increasing trends are largely hypothesized to be related to the advancement of neonatal care enabling higher survival rates among premature newborns worldwide [2], thus leading towards a growing ROP epidemic worldwide [3].

Current guidelines from the American Academy of Ophthalmology (AAO) and the American Academy of Pediatrics (AAP) recommend that infants with gestational age (GA) 30 weeks or less, birth weight $1500 \mathrm{~g}$ or less, or a complicated clinical course be screened for ROP [1]. Fundoscopic examination using binocular indirect ophthalmoscopy (BIO) is typically carried out by an ophthalmologist with expertise in the evaluation of ROP. The first examination is performed at 31 weeks postmenstrual age for infants with GA 27 weeks or less at birth, and at 4 weeks chronological age for infants born at GA 27 weeks or older [1]. The follow-up schedule depends on the level and course of maturation of the retina.

BIO examination by a trained ophthalmologist remains the gold standard for the screening of ROP. However, conventional screening methods have faced great difficulties in the last two decades [4]. In high-income countries, the number of ophthalmologists performing ROP screening has decreased significantly amid lowering reimbursement and increasing liability claims related to ROP [5]. Worldwide, the scarcity of trained ophthalmologists to screen and treat ROP is a major hurdle [6]. Additional challenges include geographic limitations (rural areas) which limit access for direct screening, difficulty implementing the infrastructure to systemically screen and track patients with electronic hospital systems, and an unknown disease burden [6]. Over the years, there has been significantly increasing interest in telemedicine-based remote digital fundus imaging (RDFI-TM) evaluation for ROP [7]. Telemedicine screening systems can reach infants in settings where in-person examination might not be readily accessible both in high- and low-income countries. Digital fundus images obtained by trained photographers are sent to a remote location for analysis by an ophthalmologist or a trained grader. Bedside examination would then be limited to cases of poor image readability and cases with high-risk features requiring treatment [8].

Currently, the only validated ocular telehealth programs widely recognized and applied are for diabetic retinopathy (DR) [9]. These are being implemented with four major categories of validation defined by the American Telemedicine Association (ATA) following stringent guidelines where threshold sensitivity and specificity for validation categories 1 and 2 need to be $80 \%$ and $95 \%$ or higher, respectively [10]. Although no such criteria exist yet for ROP telescreening, it is hoped that they will develop in the foreseeable future, since ROP is a disease that is well suited for successful screening programs owing to high disease burden in premature infants, its progression in a stepwise and documentable manner, and significant visual benefits from early treatment [1].

The explosion of publications in recent years in this domain demonstrate the growing interest and utility of telemedicine in this field of ophthalmology. In this review, the authors sought to discuss landmark advances in the field to highlight the realities of telemedicine screening of ROP both in developed and developing countries. The purpose of this narrative review was to provide an overview of the role of telemedicine in the management of retinopathy of prematurity (ROP) by bringing together seminal articles in the literature pertaining to the need for telemedicine in ROP, the methods of implementation, the outcomes from already established programs and by discussing its limitations, and the future of the field in light of the arrival of machine learning. While by no means a systematic review, this paper sought to 
provide an overview of the transformation of telemedicine-based screening for ROP from a research tool to a routinely used screening method.

\section{DISEASE CLASSIFICATION AND REFERRAL-WARRANTED ROP}

The goal of ROP screening is to recognize cases of potentially damaging ROP that necessitate treatment. ROP is classified according to the International Classification of Retinopathy of Prematurity (ICROP) that describes the disease by location (zone), stage, and extent [11]. Lower zone numbers and higher stage numbers indicate more severe ROP (Table 1). Plus disease refers to marked arteriolar tortuosity and venous engorgement of the posterior pole vasculature and signifies severe disease. Pre-plus disease refers to dilatation and tortuosity that are abnormal but less than plus disease. The first large treatment trial for ROP, the CRYO-ROP study, recommended treatment with cryotherapy when disease reached threshold severity. Threshold ROP in this study was defined as at least five contiguous or eight cumulative clock hours of stage 3 ROP in zones I and II, in the presence of plus disease (Table 2) [12]. Current treatment guidelines are based on the findings of the Early Treatment for Retinopathy of Prematurity (ETROP) trial published in 2003 [13]. Type 1 ROP refers to ROP that requires treatment and type 2 ROP refers to eyes that may be carefully monitored without treatment [13]. Eyes requiring treatment are those with any stage ROP in zone I with plus disease, stage 3 ROP in zone I without plus disease, and stage 2 or 3 ROP in zone II with plus disease [13]. Eyes that can be monitored are those with stage 1 or 2 ROP in zone I without plus disease and those with stage 3 ROP in zone II without plus disease.

Table 1 International Classification of Retinopathy of Prematurity (ICROP) includes five parameters: zone, clock hours, stage, plus and pre-plus disease

\begin{tabular}{|c|c|c|}
\hline Parameter & Description & Classification \\
\hline Zone & $\begin{array}{l}\text { Refers to the location of the disease in the retina, } \\
\text { classified in Roman numerals }\end{array}$ & $\begin{array}{l}\text { Zone I: posterior retina within } 60^{\circ} \text { from the optic disc } \\
\text { Zone II: concentric circle extending from zone I to the } \\
\text { nasal ora serrata } \\
\text { Zone III: the remaining temporal retina }\end{array}$ \\
\hline Stage & $\begin{array}{l}\text { Refers to the severity of abnormal vascularity, } \\
\text { classified in Arabic numerals }\end{array}$ & $\begin{array}{l}\text { Stage 1: demarcation line between the vascularized and } \\
\text { non-vascularized retina } \\
\text { Stage 2: demarcation line with elevation } \\
\text { Stage 3: demarcation line with fibrovascular proliferation } \\
\text { Stage 4: partial retinal detachment not involving the } \\
\text { fovea (4a) or involving the fovea (4b) } \\
\text { Stage 5: total retinal detachment }\end{array}$ \\
\hline $\begin{array}{l}\text { Clock } \\
\text { hours }\end{array}$ & \multicolumn{2}{|c|}{ Refers to the extent of the developing vasculature quantified from 1 to 12 clock hours } \\
\hline $\begin{array}{l}\text { Plus } \\
\text { disease }\end{array}$ & \multicolumn{2}{|c|}{$\begin{array}{l}\text { Arterial tortuosity and venous dilation in the posterior pole equal to or greater than in the consensus standard } \\
\text { photograph }\end{array}$} \\
\hline $\begin{array}{l}\text { Pre-plus } \\
\text { disease }\end{array}$ & \multicolumn{2}{|c|}{ Abnormal vasculature not meeting the criteria for plus disease } \\
\hline
\end{tabular}


Table 2 Summary of ROP disease descriptions based on the original classification

\begin{tabular}{|c|c|c|}
\hline Description & Classification & Studies and use \\
\hline $\begin{array}{l}\text { Threshold, type } 1 \\
\text { and type } 2 \text { ROP }\end{array}$ & $\begin{array}{l}\text { Threshold ROP } \\
\text { At least } 5 \text { contiguous or } 8 \text { cumulative clock } \\
\text { hours of stage } 3 \text { ROP in zones I and II, in the } \\
\text { presence of plus disease } \\
\text { Prethreshold type } 1 \text { ROP } \\
\text { Zone I with any stage ROP with plus disease } \\
\text { Zone I with stage } 3 \text { ROP without plus disease } \\
\text { Zone II with stage } 2 \text { or } 3 \text { ROP with plus disease } \\
\text { Prethreshold type } 2 \text { ROP } \\
\text { Zone I with stage } 1 \text { or } 2 \text { ROP without plus } \\
\text { disease } \\
\text { Zone II with stage } 3 \text { ROP without plus disease }\end{array}$ & $\begin{array}{l}\text { On the basis of the CRYO-ROP study, eyes with } \\
\text { threshold ROP benefited from therapy [12]. On } \\
\text { the basis of the ETROP study, type } 1 \text { ROP } \\
\text { indicates the need for treatment within } \\
48-72 \text { h. Type } 2 \text { ROP can be closely observed } \\
{[13]}\end{array}$ \\
\hline $\begin{array}{l}\text { Referral-warranted } \\
\text { ROP (RW-ROP) }\end{array}$ & $\begin{array}{l}\text { Zone I ROP } \\
\text { ROP stage } 3 \text { or greater in any zone } \\
\text { Presence of plus disease }\end{array}$ & $\begin{array}{l}\text { The term RW-ROP was introduced by Ells et al. } \\
\text { in } 2003 \text { and is applicable to RDFI-TM systems. } \\
\text { Eyes meeting criteria for RW-ROP must be } \\
\text { referred for a bedside BIO examination [14] }\end{array}$ \\
\hline $\begin{array}{l}\text { Clinically } \\
\text { significant ROP } \\
\text { (CSROP) }\end{array}$ & $\begin{array}{l}\text { Zone I, any ROP, without vascular dilation or } \\
\text { tortuosity } \\
\text { Zone II, stage } 2 \text { or } 3 \text {, with up to one quadrant of } \\
\text { vascular dilation and tortuosity }\end{array}$ & $\begin{array}{l}\text { CSROP was defined in the Photo-ROP study } \\
\text { [16]. CSROP, as a telemedicine referral } \\
\text { threshold, indicates the need for BIO bedside } \\
\text { examination. CSROP contains criteria from } \\
\text { type } 1 \text { ROP in addition to other factors serving } \\
\text { as a "buffer zone", minimizing the risk of } \\
\text { missing treatable disease }\end{array}$ \\
\hline $\begin{array}{l}\text { Suspected } \\
\text { treatment- } \\
\text { requiring ROP } \\
\text { (STR-ROP) }\end{array}$ & $\begin{array}{l}\text { Threshold ROP in zone II } \\
\text { Prethreshold ROP in zone I }\end{array}$ & $\begin{array}{l}\text { The term STR-ROP was introduced in Germany } \\
\text { by Lorenz et al. in } 2009 \text { [15]. The definition of } \\
\text { STR-ROP is narrower than RW-ROP and can } \\
\text { avoid unnecessary referrals, at the expense a } \\
\text { lower level of safety }\end{array}$ \\
\hline $\begin{array}{l}\text { Treatment- } \\
\text { warranted ROP } \\
\text { (TW-ROP) }\end{array}$ & $\begin{array}{l}\text { Type } 1 \text { ROP } \\
\text { Any plus disease } \\
\text { Any stage } 4 \text { or higher disease }\end{array}$ & $\begin{array}{l}\text { The definition TW-ROP is used in the } \\
\text { SUNDROP live RDFI-TM screening program. } \\
\text { The definition of TW-ROP intersects with the } \\
\text { definition of type } 1 \text { ROP, for the most part. } \\
\text { Eyes meeting criteria for TW-ROP must be } \\
\text { referred for a bedside BIO examination and } \\
\text { potential treatment [17] }\end{array}$ \\
\hline
\end{tabular}


Current telemedicine screening programs aim to identify all infants with high-risk characteristics who need in-person BIO examination for consideration of treatment. The concept of referral-warranted ROP (RW-ROP) was introduced by Ells et al. in 2003 for the detection of severe ROP features on retinal images [14]. The features of RW-ROP include the key components of type 1 and type 2 ROP as defined by the ETROP trial. Eyes that warrant a referral for a bedside examination are those with zone I ROP, ROP stage 3 or greater in any zone, and those with plus disease [14]. Alternative classifications include suspected treatment-requiring ROP (STR-ROP), clinically significant ROP (CSROP), and treatment-warranted ROP (TW-ROP) [15-17].

CSROP was defined in the Photo-ROP study as a telemedicine referral threshold indicating the need for BIO bedside examination [16]. CSROP contains criteria from type 1 ROP in addition to other factors serving as a "buffer zone" minimizing the risk of missing treatable disease and is defined as any ROP in zone I without vascular dilation or tortuosity, and, ROP stage 2 or 3 in zone II, with up to 1 quadrant of vascular dilation or tortuosity. STR-ROP was proposed by Lorenz et al. in Germany in 2009 [15] as threshold ROP in zone II or prethreshold ROP in zone I. This definition is narrower than RW-ROP and can avoid unnecessary referrals, at the expense a lower level of safety. Finally, TW-ROP was used in the SUNDROP live RDFI-TM screening program. The definition of TW-ROP intersects with the definition of type 1 ROP, for the most part. In addition to type 1 ROP, TW-ROP also includes eyes with any plus disease and any stage 4 or higher disease [17]. While there is significant overlap between the different disease classifications, those cannot be used interchangeably and, as such, comparison between studies cannot be directly made.

\section{METHODOLOGY}

The authors conducted this retrospective study by a systematic review of studies of RDFI-TM systems without meta-analysis. Articles published on the PubMed database in the last two decades found using the search terms "telemedicine" and "retinopathy of prematurity" were reviewed. All the included studies employed independent masked image graders and used ophthalmoscopic examination as the reference standard. The inclusion criteria were case-control study, meta-analysis, cohort study, clinical trials, practice guidelines, and reviews. The exclusion criteria were case reports, letters, or overviews. The authors chose to discuss only landmark studies, those that best illustrate the RDFI-TM paradigm and its evolution over time. Table 3 provides a summary of those studies and highlights important features such as the standard reference used, information about image acquisition and grading, output, and results. This review article is based on previously conducted studies and does not contain any studies with human participants or animals performed by any of the authors.

\section{EVIDENCE FOR RDFI-TM IN HIGH- INCOME COUNTRIES}

In 2003, Ells et al. published a pilot study to evaluate the use of RDFI in the diagnosis of RWROP. In a study that included 44 infants, digital photographs using RetCam-120 were obtained directly after standard BIO examination by the same examiner. A masked independent pediatric ophthalmologist located in a remote location graded and interpreted the photographs. RW-ROP was detected with a sensitivity of $100 \%$ and a specificity of $96 \%$ [14]. This study was the first to demonstrate the promising role of RDFI for telemedicine-based screening of ROP. Three years later, in 2006, Chiang et al. also used a RetCam-120 and compared it to the gold standard BIO examination [18]. In contrast to Ells' previous study, an ophthalmic photographer instead of the examiner captured the photographs of the 64 subjects [14]. Masked interpretation by three image readers resulted in a mean sensitivity of $77 \%$ and a specificity of $96 \%$ for the detection of type 2 or worse ROP. Average sensitivity and specificity were better for the detection of treatment-requiring type 1 or worse ROP, with $87 \%$ and $96 \%$, respectively 
Table 3 Summary of the evidence for RDFI-TM systems in high-income countries

\begin{tabular}{|c|c|c|c|c|c|c|}
\hline $\begin{array}{l}\text { Author, } \\
\text { year }\end{array}$ & $\begin{array}{l}\text { Standard } \\
\text { reference }\end{array}$ & Image acquisition & Image grading & $\begin{array}{l}\text { Infants } \\
(n)\end{array}$ & Outcome & Results \\
\hline $\begin{array}{c}\text { Ells et al., } \\
2003 \\
{[14]}\end{array}$ & $\mathrm{BIO}$ & Ophthalmologist & $\begin{array}{l}1 \text { masked pediatric } \\
\text { ophthalmologist }\end{array}$ & 44 & $\begin{array}{l}\text { Detection of RW- } \\
\text { ROP }\end{array}$ & $\begin{array}{l}100 \% \text { sensitivity and } \\
96 \% \text { specificity }\end{array}$ \\
\hline $\begin{array}{l}\text { Chiang } \\
\text { et al., } \\
2006 \\
{[18]}\end{array}$ & $\mathrm{BIO}$ & $\begin{array}{l}\text { Ophthalmic } \\
\text { photographer }\end{array}$ & $\begin{array}{l}3 \text { masked pediatric } \\
\text { ophthalmologists }\end{array}$ & 64 & $\begin{array}{l}\text { Detection of } \\
\text { type } 1 \text { and } \\
\text { type } 2 \text { or worse } \\
\text { ROP }\end{array}$ & $\begin{array}{l}87 \% \text { sensitivity and } 96 \% \\
\text { specificity for type } 1 \\
\text { or worse ROP; } 77 \% \\
\text { sensitivity and } 96 \% \\
\text { specificity for type } 2 \\
\text { or worse ROP }\end{array}$ \\
\hline $\begin{array}{l}\text { Wu et al., } \\
2006 \\
{[19]}\end{array}$ & $\mathrm{BIO}$ & $\begin{array}{c}\text { Ophthalmologist } \\
\text { or ophthalmic } \\
\text { photographer }\end{array}$ & $\begin{array}{l}1 \text { masked pediatric } \\
\text { ophthalmologist }\end{array}$ & 43 & $\begin{array}{l}\text { Detection of } \\
\text { type } 2 \text { ROP or } \\
\text { worse }\end{array}$ & $\begin{array}{l}100 \% \text { sensitivity and } \\
97 \% \text { specificity }\end{array}$ \\
\hline $\begin{array}{l}\text { Chiang } \\
\text { et al., } \\
2007 \\
{[20]}\end{array}$ & $\mathrm{BIO}$ & $\begin{array}{l}\text { Trained NICU } \\
\text { nurse }\end{array}$ & $\begin{array}{l}3 \text { pediatric retinal } \\
\text { ophthalmologists }\end{array}$ & 67 & $\begin{array}{l}\text { Detection of } \\
\text { type } 1 \text { and } \\
\text { type } 2 \text { or worse } \\
\text { ROP, at } \\
31-33 \text { weeks } \\
\text { GA and } \\
\text { 35-37 weeks } \\
\text { GA }\end{array}$ & $\begin{array}{l}\text { For type } 1 \text { ROP or } \\
\text { worse, } 100 \% \\
\text { sensitivity and } 89 \% \\
\text { specificity } \\
\text { (35-37 weeks). For } \\
\text { type } 2 \text { ROP or worse, } \\
76 \% \text { sensitivity and } \\
96 \% \text { specificity } \\
\text { (31-33 weeks), and, } \\
100 \% \text { sensitivity and } \\
91 \% \text { specificity } \\
\text { (35-37 weeks) }\end{array}$ \\
\hline $\begin{array}{l}\text { Photo- } \\
\text { ROP, } \\
2008 \\
{[16]}\end{array}$ & $\mathrm{BIO}$ & Ophthalmologist & $\begin{array}{l}2 \text { masked ROP } \\
\text { experts }\end{array}$ & 51 & $\begin{array}{l}\text { Detection of } \\
\text { CSROP }\end{array}$ & $\begin{array}{l}92 \% \text { sensitivity and } 37 \% \\
\text { specificity }\end{array}$ \\
\hline $\begin{array}{l}\text { Dhaliwal } \\
\text { et al., } \\
2009 \\
{[22]}\end{array}$ & $\mathrm{BIO}$ & Ophthalmologist & $\begin{array}{l}\text { By the } \\
\text { ophthalmologist } \\
\text { acquiring the } \\
\text { images }\end{array}$ & 81 & $\begin{array}{l}\text { Detection of plus } \\
\text { disease and } \\
\text { stage } 3 \text { ROP or } \\
\text { worse }\end{array}$ & $\begin{array}{l}57 \% \text { sensitivity and } 68 \% \\
\text { specificity for stage } 3 \\
\text { ROP or worse; } 80 \% \\
\text { sensitivity and } 98 \% \\
\text { specificity for plus } \\
\text { disease }\end{array}$ \\
\hline $\begin{array}{l}\text { Lorenz } \\
\text { et al., } \\
2009 \\
{[15]}\end{array}$ & $\mathrm{BIO}$ & Ophthalmologist & $\begin{array}{c}1 \text { masked pediatric } \\
\text { ophthalmologist }\end{array}$ & 1222 & $\begin{array}{l}\text { Detection of } \\
\text { STR-ROP }\end{array}$ & $\begin{array}{l}\text { 100\% sensitivity for } \\
\text { STR-ROP and } 82 \% \\
\text { PPV for referred eyes } \\
\text { requiring treatment }\end{array}$ \\
\hline
\end{tabular}


Table 3 continued

\begin{tabular}{|c|c|c|c|c|c|c|}
\hline $\begin{array}{l}\text { Author, } \\
\text { year }\end{array}$ & $\begin{array}{l}\text { Standard } \\
\text { reference }\end{array}$ & Image acquisition & Image grading & $\begin{array}{l}\text { Infants } \\
(n)\end{array}$ & Outcome & Results \\
\hline $\begin{array}{l}\text { Dai et al., } \\
2011 \\
{[21]}\end{array}$ & $\mathrm{BIO}$ & Ophthalmologist & $\begin{array}{l}1 \text { masked pediatric } \\
\text { ophthalmologist }\end{array}$ & 108 & $\begin{array}{l}\text { Detection of } \\
\text { type } 1 \text { ROP or } \\
\text { worse }\end{array}$ & $\begin{array}{l}\text { 100\% sensitivity, } 98 \% \\
\text { specificity; } 88 \% \text { PPV } \\
\text { and 100\% NPV }\end{array}$ \\
\hline $\begin{array}{l}\text { e-ROP, } \\
\text { Quinn } \\
\text { et al., } \\
2014 \\
\text { [23] }\end{array}$ & $\mathrm{BIO}$ & $\begin{array}{l}\text { Nonphysician } \\
\text { personnel } \\
\text { including } \\
\text { NICU nurses, } \\
\text { ophthalmic } \\
\text { photographers } \\
\text { and technicians }\end{array}$ & $\begin{array}{l}2 \text { trained, masked } \\
\text { non-physician } \\
\text { readers }\end{array}$ & 1257 & $\begin{array}{l}\text { Detection of RW- } \\
\text { ROP }\end{array}$ & $\begin{array}{l}90 \% \text { sensitivity and } 87 \% \\
\text { specificity; } 63 \% \mathrm{PPV} \\
\text { and } 97 \% \mathrm{NPV}\end{array}$ \\
\hline
\end{tabular}

$B I O$ binocular indirect ophthalmoscopy, $R O P$ retinopathy of prematurity, $R W$ - $R O P$ referral-warranted ROP (see Table 2), NICU neonatal intensive-care unit, GA gestational age, CSROP clinically significant ROP (see Table 2), STR-ROP suspected treatment-requiring ROP (see Table 2), NPV negative predictive value, $P P V$ positive predictive value

[18]. Also in 2006, $\mathrm{Wu}$ et al. published the results of their cohort study that included 43 infants with bilateral examinations. Images were obtained by a pediatric ophthalmologist or an ophthalmic photographer and they were graded by a different pediatric ophthalmologist. No cases of threshold or plus disease were missed. The sensitivity was $100 \%$ and the specificity was 97\% compared with BIO examination [19].

Unlike previous studies that relied on ophthalmic professionals for image acquisition, in the 2007 study by Chiang et al., images were obtained by a trained NICU nurse. The prospective cohort consisted of 67 infants. Sets of three to five wide-angle photographs obtained by a trained nurse were read by three pediatric retinal specialists [20]. Compared to standard BIO examination by a pediatric ophthalmologist, the average sensitivity and specificity varied depending on the date of image acquisition. For examinations performed at 31-33 weeks postmenstrual age, the mean sensitivity for detection of type 2 or worse ROP was $76 \%$ and the specificity was $96 \%$. The sensitivity was better for the 35-37 week photos, reaching $100 \%$ sensitivity and $91 \%$ specificity for the detection of type 2 or worse ROP. Similarly, the average sensitivity for type 1 or worse ROP was $100 \%$ and the specificity was $89 \%$ [20]. The Photographic Screening for Retinopathy of Prematurity (Photo-ROP) study was a prospective multicentric study published in 2008 that analyzed 300 examinations from 51 infants obtained between 2001 and 2002 [16]. Photographs were taken by an ophthalmologist and graded by two masked ROP specialists. The ability to detect CSROP, as defined in the study, was as follows: $92 \%$ sensitivity and $37 \%$ specificity. In other words, the screening program was excellent at catching CSROP when the image quality was high [16]. However, the low specificity suggested a high false positive rate, meaning that many infants were referred for BIO examination when they did not need it.

Results in other high-income countries such as the UK, New Zealand, and Germany, using similar study designs, also yielded strong results for ROP detection using RDFI-TM [15, 21, 22]. In the UK, Dhaliwal et al. performed a study in which two ROP specialists were randomized to using either wide-angle retinal photography or standard BIO examination in the screening and 
management of ROP [22]. No remote image grading was performed. Sensitivity for retinal photography to detect stage 3 ROP or worse was $57 \%$, lower than in most studies. Nonetheless, there was $80 \%$ sensitivity and $98 \%$ specificity for the detection of plus disease [22]. In Germany, long-term results from a multicentric study that included 1222 infants were published by Lorenz et al. in 2009 [15]. Images were acquired by ophthalmologists and grading was performed by a masked experienced pediatric ophthalmologist in a remote reading center. Compared to BIO examination, the sensitivity for the detection of STR-ROP was 100\%. Interestingly, among the eyes referred for BIO evaluation, $88 \%$ required laser treatment, yielding a very high positive predictive value (PPV) for this referral criteria [15]. In New Zealand, Dai el al. published a study that included 422 examinations from 108 infants who were screened using RDFI-TM and concurrent BIO examinations, performed by one ophthalmologist [21]. Image grading was performed remotely by a masked pediatric ophthalmologist. Compared to $\mathrm{BIO}$ examination, the sensitivity for detecting type 1 ROP or worse was $100 \%$ and the specificity was $98 \%$. The negative predictive value (NPV) was $100 \%$, meaning that no cases of type 1 ROP or worse were erroneously classified as normal [21].

For the first time, in 2014, the Telemedicine Approaches to Evaluating Acute-Phase ROP (eROP) study demonstrated the validity of RDFITM image grading by nonphysician readers in a large multicentric study that included 5520 examinations from 1257 infants. Images were also acquired by nonphysician personnel including NICU nurses and ophthalmic photographers and technicians. The outcome measure was the detection of RW-ROP. The sensitivity was $90 \%$ and the specificity was $87 \%$. The negative and positive predictive values were $97 \%$ and $63 \%$, respectively [23].

The early studies on the effectiveness and safety of RDFI-TM systems for the screening of ROP laid the groundwork for the currently available live screening programs. One of the largest currently available programs implementing RDFI-TM is the Stanford University Network for Diagnosis of Retinopathy of
Prematurity (SUNDROP) [17]. Images are acquired by trained NICU nurses in six satellite NICUs located across Northern California. Images are sent to the Stanford University Byers Eye Institute reading center for remote interpretation by a ROP specialist. In the SUNDROP program, the telemedicine-based screening is the sole in-hospital screening technique. However, as stipulated in the AAO/AAP guidelines, a BIO examination is obtained at discharge. This examination helped serve as a standard reference in the evaluation of the screening program's outcome which was the detection of TW-ROP [17].

Six-year data from the SUNDROP program were published by Wang et al. in 2015. During the 6 years, 2169 examinations of 1216 eyes (608 infants) were performed, generating 26,970 retinal images. The rate of TW-ROP was $3.6 \%$. Compared to BIO examination the sensitivity of the screening program was $100 \%$, the specificity $99.8 \%$, the positive predictive value $95.5 \%$, and the negative predictive value $100 \%$. This real-world data is the strongest evidence that telemedicine is safe and reliable for the screening of ROP [17].

\section{UNIQUE APPROACHES FOR RDFI- TM IN MIDDLE- AND LOW- INCOME COUNTRIES: THE KIDROP EXAMPLE}

In 2010, an estimated 184,700 premature infants developed ROP worldwide, of whom 7\% developed mild-to-moderate visual impairment and $11 \%$ became blind from the disease [24]. Rapid medical progress in many middle- and low-income countries has resulted in service expansion for neonates leading to increased survival of premature infants. However, the lack of structured frameworks for ROP screening in those countries has led to a significant increase in the incidence of the disease [6].

Some of the challenges faced by countries like India for managing ROP include lack of awareness for the disease among care-givers, inadequately trained personnel for screening and treatment, geographic limitations and lack 
of resources in rural areas, and large numbers of infants to screen since ROP manifests in heavier weight premature infants (birth weight $2000 \mathrm{~g}$ and less) $[3,6,25]$. One successful program to address ROP screening in India has been the Karnataka Internet Assisted Diagnosis of ROP (KIDROP) program. Since its inception, this non-traditional RDFI-TM system has allowed the screening of more than 45,000 infants from 126 centers in Southern India and the treatment of 2250 infants [6].

The program employs ROP imagers who travel with mobile units to visit specific NICUs on a fixed schedule. On average, each team would visit 16-28 NICUs weekly and travels around $1500 \mathrm{~km}$ each week [25]. The imagers consisted of pediatric optometrists and ophthalmic photographers who received a threelevel accreditation that takes up to 90 days to complete [26]. Image acquisition would be performed by the imagers using a RetCam camera and interpretation would be performed in real time by the same trained imager. Decision triage was based on specific criteria: red (type 1 ROP or worse, requiring urgent evaluation by an expert), orange (type 2 ROP, requiring followup), and green (discharge). This provided the parents with an immediate management plan with a diagnosis and next date for follow-up, thereby decreasing the administrative burden of communicating the decisions at a later time to the parents [25].

As a safety net, images were also transferred to a remote online platform accessible by smartphone for near-live reports by ROP experts. Images from severe cases were uploaded first and the turnover cycle from uploading to obtaining expert opinion was less than $10 \mathrm{~min}$ in some cases [26]. Results from the screening of 1601 infants in KIDROP program were published in 2014 by Vinekar et al. [25]. The highest-level technicians agreed with $94 \%$ of expert decisions. For the detection of type 1 ROP or worse, the sensitivity was $96 \%$, the specificity $93 \%$, and the positive and negative predictive values were $82 \%$ and $99 \%$, respectively. As such, fewer than $1 \%$ of infants requiring treatment would have been missed [25].

\section{FRAMEWORK FOR LIVE RDFI-TM PROGRAMS}

The AAO/AAP guidelines for telemedicine for the evaluation of ROP describe the practical framework for RDFI-TM systems [7]. The guidelines are described in this ensuing section in light of recent advances in smartphone imaging.

Dilation is performed with phenylephrine $2.5 \%$ and tropicamide 1\%, or Cyclomydril (cyclopentolate $0.2 \%$ with phenylephrine $1 \%$; Alcon Laboratories, Fort Worth, TX). Six clear images per eye are captured, centered on the following locations: anterior segment and iris (to assess dilation and other pathology), optic disc, temporal retina, nasal retina, superior retina, and inferior retina [7]. Image acquisition is often performed by trained NICU nurses, information technology personnel, or other caregivers. The guidelines stipulate that nurse team members should be trained by a certified ophthalmic photographer or someone familiar with fundus photography [7]. Given the absence of formal certification programs, oversight by the ophthalmologist is often required to provide insight about the quality of the acquired images. While nonphysician image graders have been used within clinical trials (eROP, Quinn et al.), current guidelines recommend that remote image grading should only be done by ophthalmologists [7, 23]. The absence of a formal certification process prevents the routine use of nonphysician graders.

The gold standard camera currently used is the RetCam family of cameras (Clarity Medical Systems, Pleasanton, CA, USA). This system is contact-based and uses a coupling agent between the camera lens and cornea. Wide-angle photography with a $130^{\circ}$ field-of-view of the fundus is preferred. Recently, novel noncontact digital cameras and smartphone-based imaging systems were developed for imaging the pediatric retina [27-31]. An RDFI-TM system based on the Pictor noncontact camera has been shown to have high sensitivity and specificity for detecting pre-plus and plus disease, at levels comparable to RetCam-based RDFI [29]. 
Similarly, smartphone-based imaging systems like RetinaScope have also been used to image premature infants. The device captures $50^{\circ}$ fundus images which can be stitched together to generate a wide-field montage of the retina [28]. In 2019, Patel et al. tested RetinaScope's ability to detect plus disease in patients with ROP [27]. Fifty-four eyes of 27 premature infants were imaged using RetinaScope. Images were reviewed by two masked ROP specialists who determined the image quality and the presence or absence of ROP and plus disease. Images were considered acceptable or excellent in more than $95 \%$ of cases. There was strong intergrader agreement for the presence of any retinopathy on the digital images (Cohen's $\kappa=0.92$ ). Also, there was substantial agreement between image-based diagnosis and standard BIO examination for the detection of plus disease $(\kappa=0.85)$ [27].

In parallel, the MII Ret Cam device has also emerged as a powerful tool in smartphonebased imaging in ROP [32, 33]. The device is used with a 20-diopter lens and a smartphone in video mode (with flash) to perform indirect ophthalmoscopy by an ROP specialist. In a pilot study of 20 premature infants (27 eyes), still pictures obtained with the MII Ret Cam device were extracted from the videos and analyzed by two masked ROP specialists. There was strong intergrader agreement between the gold standard BIO examination and the photographic evaluation (Cohen's $\kappa=1.0$ ) for referable cases and moderate agreement ( $\kappa$ range, $0.62-0.78$ ) for staging, zone, and plus disease status [31].

\section{DATA TRANSFER}

Currently, the most widely used model for RDFI-TM for ROP is the store-and-forward (asynchronous) model. Image acquisition and image grading are separated in time and place. Data is transferred over the internet and reading physicians are notified by e-mail, fax, or telephone. Data from the infant's chart like birth weight, gestational age, weight, and medical history are sent along with the photos. Physicians are required to provide an "impression" and recommendations within a pre-set time frame and must recognize and follow up on non-ROP incidental ocular findings such as optic nerve colobomas [7]. Currently, eligibility for screening termination cannot be determined using RDFI-TM systems. As such, each infant who has undergone ROP screening must be examined using BIO before discharge or within $72 \mathrm{~h}$ of discharge, as defined by the AAO guidelines [1]. The cessation of ROP surveillance in those infants should be expected to decrease the burden for ophthalmologists, infants, and their families.

\section{ARTIFICIAL INTELLIGENCE IN ROP}

The diagnostic ability of ophthalmologists grading images in an RDFI-TM system depends on their capacity to recognize clinical patterns based on retinal appearance and vascular architecture. In a similar fashion, computerbased image analysis (CBIA) systems of fundus images can generate a diagnostic output based on predetermined image characteristics [34-36]. In the past decade, systems like ROPTool, Vessel Map, Retinal Image multiScale Analysis (RISA), and Computer Assisted Image Analysis of the Retina (CAIAR) have emerged to help clinicians recognize plus disease [37]. These systems consisted of feature extraction-based systems that quantified vascular dilation and tortuosity into a value that had diagnostic agreement with the clinical diagnosis of ROP as established by multiple expert clinicians (standard reference) [38]. Although promising, the accuracy of these systems' outputs alone was not sufficient for wide adoption at the bedside or within RDFITM systems.

More recently, models using artificial intelligence (AI) have been developed to recognize plus disease [38]. Table 4 provides a summary of major machine learning models developed for the detection of plus disease in ROP. Machine learning is a subtype of AI that can be applied to image analysis in RDFI-TM systems. Supervised machine learning describes algorithms that can apply what has been learned in the past to new data using labeled examples [39]. In 2015, Ataer-Cansizoglu et al. described the Imaging and Informatics in ROP (i-ROP) model that uses 
Table 4 Summary of major machine learning models developed for the detection of plus disease in ROP

\begin{tabular}{|c|c|c|c|c|c|c|c|}
\hline System & Reference & $\begin{array}{l}\text { Type of } \\
\text { machine } \\
\text { learning }\end{array}$ & Algorithm & Output & $\begin{array}{l}\text { Vascular } \\
\text { feature } \\
\text { analyzed }\end{array}$ & Results & Limitations \\
\hline $\begin{array}{l}\text { i-ROP, Ataer- } \\
\text { Cansizoglu } \\
\text { et al., } 2015 \\
\text { [52] }\end{array}$ & $\begin{array}{l}\text { Consensus } \\
\text { of } 3 \\
\text { ROP } \\
\text { experts }\end{array}$ & $\begin{array}{c}\text { Supervised } \\
\text { learning }\end{array}$ & SVM & $\begin{array}{l}\text { Plus } \\
\text { disease } \\
\text { vs. } \\
\text { normal }\end{array}$ & $\begin{array}{l}\text { Tortuosity } \\
\text { of } \\
\text { arterioles } \\
\text { and } \\
\text { venules } \\
\text { together }\end{array}$ & $\begin{array}{l}\text { 95\% accuracy } \\
\text { (experts: } 96 \% \text {, } \\
\text { 94\%, and 92\%) } \\
\text { for classifying } \\
\text { plus disease } \\
\text { compared to } \\
\text { normal }\end{array}$ & $\begin{array}{l}\text { Requires manual } \\
\text { vessel tracing } \\
\text { and } \\
\text { segmentation as } \\
\text { an input }\end{array}$ \\
\hline $\begin{array}{l}\text { Worrall et al., } \\
2016 \text { [40] }\end{array}$ & $\begin{array}{l}\text { Expert- } \\
\text { labelled } \\
\text { data }\end{array}$ & $\begin{array}{c}\text { Supervised } \\
\text { learning }\end{array}$ & $\mathrm{CNN}$ & $\begin{array}{l}\text { Plus } \\
\text { disease } \\
\text { vs. } \\
\text { normal }\end{array}$ & $\begin{array}{l}\text { Tortuosity } \\
\text { and } \\
\text { dilation } \\
\text { of vessels }\end{array}$ & $\begin{array}{l}92 \% \text { accuracy, } \\
82.5 \% \text { sensitivity, } \\
\text { and } 98 \% \\
\text { specificity }\end{array}$ & $\begin{array}{l}\text { Despite being } \\
\text { automated, } \\
\text { required the use } \\
\text { of human- } \\
\text { dependant } \\
\text { labels }\end{array}$ \\
\hline $\begin{array}{l}\text { i-ROP DL, } \\
\text { Brown } \\
\text { et al., } 2018 \\
\text { [42] }\end{array}$ & $\begin{array}{l}\text { Expert- } \\
\text { labelled } \\
\text { data }\end{array}$ & $\begin{array}{r}\text { Supervised } \\
\text { learning }\end{array}$ & CNN & $\begin{array}{l}\text { Plus } \\
\text { disease } \\
\text { vs. pre- } \\
\text { plus } \\
\text { disease } \\
\text { vs. } \\
\text { normal }\end{array}$ & $\begin{array}{l}\text { Not } \\
\quad \text { reported }\end{array}$ & $\begin{array}{l}\text { For plus disease, } \\
93 \% \text { sensitivity } \\
\text { and } 94 \% \\
\text { specificity } \\
\text { For pre-plus } \\
\text { disease, } 100 \% \\
\text { sensitivity and } \\
\text { 94\% specificity }\end{array}$ & None identified \\
\hline $\begin{array}{l}\text { ROP.AI, Tan } \\
\text { et al. [41] }\end{array}$ & $\begin{array}{l}1 \text { ROP } \\
\text { expert }\end{array}$ & $\begin{array}{r}\text { Supervised } \\
\text { learning }\end{array}$ & CNN & $\begin{array}{l}\text { Plus } \\
\text { disease } \\
\text { vs. pre- } \\
\text { plus } \\
\text { disease } \\
\text { vs. } \\
\text { normal }\end{array}$ & $\begin{array}{l}\text { Not } \\
\text { reported }\end{array}$ & $\begin{array}{l}\text { For plus disease, } \\
97 \% \text { sensitivity } \\
\text { and } 98 \% \text { NPV }\end{array}$ & $\begin{array}{l}\text { Data from a single } \\
\text { clinician, not } \\
\text { taking into } \\
\text { account real- } \\
\text { world } \\
\text { interclinician } \\
\text { variations }\end{array}$ \\
\hline
\end{tabular}

$S V M$ support vector machine, $C N N$ convoluted neural network, $N P V$ negative predictive value

support vector machine (SVM), a type of supervised machine learning that was trained to classify images on the basis of manual tracing and segmentation of the retinal vessels as an input. The model had 95\% accuracy (experts: $96 \%, 94 \%$, and $92 \%$ ) for classifying plus disease compared to reference standards as determined consensus of three expert ROP image graders and clinical examination.
In 2016, Worall et al. demonstrated a plus disease detection tool using deep learning by employing convolutional neural networks (CNNs) [40]. CNNs automatically extract various type of image features that might be indicative of disease, as learned from a training set of images [39]. Worrall et al. used real-world datasets from Canada (1459 images) and the UK (106 images) labeled in a binary fashion: plus vs. 
no plus disease. For the diagnosis of plus disease, the accuracy was $92 \%$, the sensitivity $82.5 \%$, and the specificity $98 \%$. The authors concluded that the classifier demonstrated good agreement with the expert labelers but also highlighted the limitations associated with the use of human-dependent training sets, since significant discrepancies can be present between clinicians in regards to plus disease diagnosis [40].

With this in mind, Tan et al. trained a CNN model using almost 7000 fundus images labeled by a single clinician at a single institution. The model detected plus disease with $97 \%$ sensitivity and 98\% negative predictive value. These results are highly promising but additional work is needed to determine its real-world applicability to account for inter-clinician variations in the diagnosis of plus disease [41]. In a different approach to improve the reliability of training sets, Brown et al. used a reference standard diagnosis (RSD). RSD is founded on consensus diagnosis from multiple image gradings as well as a clinical diagnosis [42]. The i-ROP DL model, built to detect plus disease, was trained with data labeled with an RSD [42]. This algorithm diagnosed plus disease with comparable accuracy to human experts: 93\% sensitivity and 94\% specificity for plus disease and $100 \%$ sensitivity and $94 \%$ specificity for pre-plus disease [42].

\section{DISCUSSION}

Over the last two decades, telemedicine-based remote digital fundus imaging (RDFI-TM) evaluation for ROP gradually transitioned from being a research tool to becoming a routinely used method of ROP screening alongside BIO examination. As shown above, a large number of studies have proven the ability of RDFI-TM to detect ROP with good sensitivity and specificity compared to the gold standard BIO bedside examination. The favorable results were also demonstrated in the real-world setting as evidenced by the success of the SUNDROP and KIDROP programs [17].

Standard BIO examination remains the gold standard for ROP screening. It is performed in real time and allows better visualization of zone III and an increased sense of depth for disease staging. However, ophthalmoscopy has multiple limitations. It is performed in a relatively unfamiliar setting for the ophthalmologist, on an infant attached to life-sustaining equipment, which can be challenging [43]. There is also a shortage of ophthalmologists trained and willing to screen for ROP in resource-limited communities. The main benefit of RDFI-TM is increasing the accessibility of screening in both in high- and low-income countries. In high-income countries, amid a decrease in the number of ophthalmologists performing ROP screening, RDFI-TM programs can complement the screening effort. In lowincome countries, RDFI-TM systems (like KIDROP) have successfully reached infants that would have otherwise not had access to ROP screening because of geographic and resource limitations. Another benefit of RDFI-TM is that image acquisition and image grading are often separated in time and place, allowing for a more objective and less distracting evaluation by the ROP specialist. Digital image acquisition allows for objective documentation of findings, facilitating future consultation and serving as evidence for medicolegal purposes [43].

RDFI-TM evaluation for ROP has also been shown to be more cost-effective than traditional ophthalmologist-driven screening [44]. In 2008, Jackson et al. published a cost-utility analysis comparing telemedicine and ophthalmoscopy for ROP management [45]. Both screening methods were shown to be highly cost-effective compared to other healthcare interventions. Telemedicine was, however, more cost-effective than standard ophthalmoscopy. The cost per quality-adjusted life year gained was $\$ 3193$ with telemedicine compared to $\$ 5617$ with standard ophthalmoscopy [45]. The feasibility of telemedicine-based screening programs in developing nations remains unclear, despite some encouraging results $[25,46]$. Developing countries face multiple challenges for the implantation of telemedicine including state-level policies, budgetary constraints, and issues with cultural perception [47]. The biggest barrier seems to be the lack of formal organizational structures to dispense telemedicine-related services. Also, despite being considered cost- 
effective in developed nations, the deployment of telemedicine-related services can have high initial start-up and running costs including purchasing a wide-angle telemedicine camera, setting up an computer network, and paying internet and electricity bills, salary of support staff, and physician reimbursement [47]. Nonetheless, this seems to be changing as more and more developing countries adopt screening for retinal disease such as diabetic retinopathy, which is a good prognosticator for ROP RDFITM screening in these regions $[48,49]$.

The role for CBIA and deep learning-based screening systems has grown over the years. As part of an RDFI-TM program, a deep learning algorithm can perform a preliminary triage before the ophthalmologist's evaluation and has the potential to replace the image reader altogether, with greater efficacy which may increase screening rates. Currently available algorithms have demonstrated capacity to detect plus disease, a diagnostic classification that expert ophthalmologists frequently disagree on (Table 4). Nonetheless, CBIA for ROP that is trained with human-labelled inputs should be used with caution since they can be prone to bias and disparity with relatively small training sets and high intergrader variability. Deep learning in ROP screening holds great promise but remains a research tool at the current moment. As we learn more and more about the real-life deployment of such systems in the screening of diabetic retinopathy, we will be able to better address its ethical, medicolegal, and logistic considerations.

Novel retinal imaging devices have emerged in the last decade and have the potential for improving image acquisition in telemedicinebased ROP screening programs. Some evidence suggests that telemedicine examination may be less stressful than standard BIO examination for premature infants [50]. Similarly, the use of novel noncontact cameras that avoid the use of a lid speculum and topical anesthesia might provide additional safety benefits for those infants. In parallel, smartphone-based imaging tools may be useful for screening ROP. Such devices leverage on the smartphone's built-in high-resolution camera, computing power, and data transfer capacities (e.g., Wi-Fi). For low- resource communities and developing countries who face budgetary constraints for the set-up of RDFI-TM programs, smartphone-based imaging tools can be particularly valuable [51].

\section{CONCLUSIONS}

Telemedicine-based remote digital fundus imaging offers a validated and viable alternative to in-person, on-site indirect ophthalmoscopy examination of the premature infant by an ophthalmologist for the screening of retinopathy of prematurity. While the latter remains the gold standard for ROP screening, advances in imaging technology, rapid evolution in portable retinal imaging systems, and the rise of automated image interpretation offer great promise in drastically expanding the accessibility of telemedicine-based screening of retinopathy of prematurity worldwide.

\section{ACKNOWLEDGMENTS}

Funding. No funding or sponsorship was received for this study or the publication of this article.

Authorship. All named authors meet the International Committee of Medical Journal Editors (ICMJE) criteria for authorship for this article, take responsibility for the integrity of the work as a whole, and have given their approval for this version to be published.

Disclosures. Fares Antaki, Kenan Bachour, Tyson N. Kim, and Cynthia X. Qian declare that they have no conflict of interest.

Compliance with Ethics Guidelines. This article is based on previously conducted studies and does not contain any studies with human participants or animals performed by any of the authors.

Data Availability. Data sharing is not applicable to this article as no datasets were generated or analyzed during the current study. 
Open Access. This article is licensed under a Creative Commons Attribution-NonCommercial 4.0 International License, which permits any non-commercial use, sharing, adaptation, distribution and reproduction in any medium or format, as long as you give appropriate credit to the original author(s) and the source, provide a link to the Creative Commons licence, and indicate if changes were made. The images or other third party material in this article are included in the article's Creative Commons licence, unless indicated otherwise in a credit line to the material. If material is not included in the article's Creative Commons licence and your intended use is not permitted by statutory regulation or exceeds the permitted use, you will need to obtain permission directly from the copyright holder. To view a copy of this licence, visit http:// creativecommons.org/licenses/by-nc/4.0/. REFERENCES

1. Fierson WM, American Academy of Pediatrics Section on Ophthalmology, American Academy of Ophthalmology, American Association for Pediatric Ophthalmology and Strabismus, American Association of Certified Orthoptists. Screening examination of premature infants for retinopathy of prematurity. Pediatrics. 2018;142(6):e20183061.

2. Ludwig CA, Chen TA, Hernandez-Boussard T, Moshfeghi AA, Moshfeghi DM. The epidemiology of retinopathy of prematurity in the United States. Ophthalmic Surg Lasers Imaging Retina. 2017;48(7):553-62.

3. Gilbert C. Retinopathy of prematurity: a global perspective of the epidemics, population of babies at risk and implications for control. Early Hum Dev. 2008;84(2):77-82.

4. Mills MD. Retinopathy of prematurity malpractice claims. Arch Ophthalmol. 2009;127(6):803-4.

5. Day S, Menke AM, Abbott RL. Retinopathy of prematurity malpractice claims: the Ophthalmic Mutual Insurance Company experience. Arch Ophthalmol. 2009;127(6):794-8.

6. Vinekar A, Dogra M, Azad RV, Gilbert C, Gopal L, Trese M. The changing scenario of retinopathy of prematurity in middle and low income countries: unique solutions for unique problems. Indian J Ophthalmol. 2019;67(6):717-9.
7. Fierson WM, Capone A, American Academy of Pediatrics Section on Ophthalmology, American Academy of Ophthalmology, American Association of Certified Orthoptists. Telemedicine for evaluation of retinopathy of prematurity. Pediatrics. 2015;135(1):e238-e254254.

8. Bowe T, Ung C, Campbell JP, Yonekawa Y. Telemedicine for retinopathy of prematurity in 2020 . J VitreoRetinal Dis. 2019;3(6):452-8.

9. Horton MB, Brady CJ, Cavallerano J, et al. Practice guidelines for ocular telehealth-diabetic retinopathy. Telemed e-Health. 2020;26(4):495-54343.

10. Li HK, Horton M, Bursell SE, et al. Telehealth practice recommendations for diabetic retinopathy, second edition. Telemed J e-Health. 2011;17(10): 814-37.

11. International Committee for the Classification of Retinopathy of Prematurity. The International Classification of Retinopathy of Prematurity revisited. Arch Ophthalmol. 2005;123(7):991-9.

12. Mills MD. Evaluating the cryotherapy for retinopathy of prematurity study (CRYO-ROP). Arch Ophthalmol. 2007;125(9):1276-81.

13. Early Treatment for Retinopathy of Prematurity Cooperative Group. Revised indications for the treatment of retinopathy of prematurity: results of the early treatment for retinopathy of prematurity randomized trial. Arch Ophthalmol. 2003;121(12): 1684-94.

14. Ells AL, Holmes JM, Astle WF, et al. Telemedicine approach to screening for severe retinopathy of prematurity: a pilot study. Ophthalmology. 2003;110(11):2113-7.

15. Lorenz B, Spasovska K, Elflein H, Schneider N. Widefield digital imaging based telemedicine for screening for acute retinopathy of prematurity (ROP). Sixyear results of a multicentre field study. Graefes Arch Clin Exp Ophthalmol. 2009;247(9):1251-62.

16. Photographic Screening for Retinopathy of Prematurity Cooperative Group. The photographic screening for retinopathy of prematurity study (photo-ROP). Primary outcomes. Retina. 2008;28(3 Suppl):S47-54.

17. Wang SK, Callaway NF, Wallenstein MB, Henderson MT, Leng T, Moshfeghi DM. SUNDROP: six years of screening for retinopathy of prematurity with telemedicine. Can J Ophthalmol. 2015;50(2): 101-6.

18. Chiang MF, Keenan JD, Starren J, et al. Accuracy and reliability of remote retinopathy of prematurity diagnosis. Arch Ophthalmol. 2006;124(3):322-7. 
19. Wu C, Petersen RA, VanderVeen DK. RetCam imaging for retinopathy of prematurity screening. J AAPOS. 2006;10(2):107-11.

20. Chiang MF, Wang L, Busuioc M, et al. Telemedical retinopathy of prematurity diagnosis: accuracy, reliability, and image quality. Arch Ophthalmol. 2007;125(11):1531-8.

21. Dai S, Chow K, Vincent A. Efficacy of wide-field digital retinal imaging for retinopathy of prematurity screening. Clin Exp Ophthalmol. 2011;39(1): 23-9.

22. Dhaliwal C, Wright E, Graham C, McIntosh N, Fleck BW. Wide-field digital retinal imaging versus binocular indirect ophthalmoscopy for retinopathy of prematurity screening: a two-observer prospective, randomised comparison. Br J Ophthalmol. 2009;93(3):355-9.

23. Quinn GE, Ying GS, Daniel E, et al. Validity of a telemedicine system for the evaluation of acutephase retinopathy of prematurity. JAMA Ophthalmol. 2014;132(10):1178-84.

24. Blencowe H, Lawn JE, Vazquez T, Fielder A, Gilbert C. Preterm-associated visual impairment and estimates of retinopathy of prematurity at regional and global levels for 2010. Pediatr Res. 2013;74(Suppl $1): 35-49$.

25. Vinekar A, Gilbert C, Dogra M, et al. The KIDROP model of combining strategies for providing retinopathy of prematurity screening in underserved areas in India using wide-field imaging, telemedicine, non-physician graders and smart phone reporting. Indian J Ophthalmol. 2014;62(1):41-9.

26. Vinekar A, Jayadev C, Bauer N. Need for telemedicine in retinopathy of prematurity in middleincome countries: e-ROP vs KIDROP. JAMA Ophthalmol. 2015;133(3):360-1.

27. Patel TP, Aaberg MT, Paulus YM, et al. Smartphonebased fundus photography for screening of plusdisease retinopathy of prematurity. Graefes Arch Clin Exp Ophthalmol. 2019;257(11):2579-85.

28. Patel TP, Kim TN, Yu G, et al. Smartphone-based, rapid, wide-field fundus photography for diagnosis of pediatric retinal diseases. Transl Vis Sci Technol. 2019;8(3):29.

29. Prakalapakorn SG, Wallace DK, Freedman SF. Retinal imaging in premature infants using the Pictor noncontact digital camera. J AAPOS. 2014;18(4):321-6.

30. Kim TN, Myers F, Reber C, et al. A smartphonebased tool for rapid, portable, and automated widefield retinal imaging. Transl Vis Sci Technol. 2018;7(5):21.
31. Sharma A, Goyal A, Bilong Y, et al. Comparison of a smartphone-based photography method with indirect ophthalmoscopic assessment in referable retinopathy of prematurity: a smart retinopathy of prematurity model pilot study. Ophthalmol Retina. 2019;3(10):911-2.

32. Sharma A, Subramaniam SD, Ramachandran KI, Lakshmikanthan C, Krishna S, Sundaramoorthy SK. Smartphone-based fundus camera device (MII Ret Cam) and technique with ability to image peripheral retina. Eur J Ophthalmol. 2016;26(2):142-4.

33. Goyal A, Giridhar A, Gopalakrishnan M, Thachil T. Neonatal intensive care unit-based screening program for retinopathy of prematurity and its treatment in an Indian population. Indian J Ophthalmol. 2019;67(6):828-33.

34. Campbell JP, Ataer-Cansizoglu E, Bolon-Canedo V, et al. Expert diagnosis of plus disease in retinopathy of prematurity from computer-based image analysis. JAMA Ophthalmol. 2016;134(6):651-7.

35. Chiang MF, Jiang L, Gelman R, Du YE, Flynn JT. Interexpert agreement of plus disease diagnosis in retinopathy of prematurity. Arch Ophthalmol. 2007;125(7):875-80.

36. Rao R, Jonsson NJ, Ventura C, et al. Plus disease in retinopathy of prematurity: diagnostic impact of field of view. Retina. 2012;32(6):1148-55.

37. Wittenberg LA, Jonsson NJ, Chan RV, Chiang MF. Computer-based image analysis for plus disease diagnosis in retinopathy of prematurity. J Pediatr Ophthalmol Strabismus. 2012;49(1):11-9 (quiz 0, 20).

38. Scruggs BA, Chan RVP, Kalpathy-Cramer J, Chiang MF, Campbell JP. Artificial intelligence in retinopathy of prematurity diagnosis. Transl Vis Sci Technol. 2020;9(2):5.

39. Grewal PS, Oloumi F, Rubin U, Tennant MTS. Deep learning in ophthalmology: a review. Can J Ophthalmol. 2018;53(4):309-13.

40. Worrall DE, Wilson CM, Brostow GJ, editors. Automated retinopathy of prematurity case detection with convolutional neural networks. Cham: Springer; 2016.

41. Tan Z, Simkin S, Lai C, Dai S. Deep learning algorithm for automated diagnosis of retinopathy of prematurity plus disease. Transl Vis Sci Technol. 2019;8(6):23.

42. Brown JM, Campbell JP, Beers A, et al. Automated diagnosis of plus disease in retinopathy of prematurity using deep convolutional neural networks. JAMA Ophthalmol. 2018;136(7):803-10. 
43. Weaver DT. Telemedicine for retinopathy of prematurity. Curr Opin Ophthalmol. 2013;24(5): 425-31.

44. Isaac $\mathrm{M}$, Isaranuwatchai $\mathrm{W}$, Tehrani N. Cost analysis of remote telemedicine screening for retinopathy of prematurity. Can J Ophthalmol. 2018;53(2): 162-7.

45. Jackson KM, Scott KE, Graff Zivin J, et al. Costutility analysis of telemedicine and ophthalmoscopy for retinopathy of prematurity management. Arch Ophthalmol. 2008;126(4):493-9.

46. Skalet AH, Quinn GE, Ying GS, et al. Telemedicine screening for retinopathy of prematurity in developing countries using digital retinal images: a feasibility project. J AAPOS. 2008;12(3):252-8.

47. Bali S. Barriers to development of telemedicine in developing countries. Telehealth. IntechOpen; 2018. https://doi.org/10.5772/intechopen.81723.

48. Salamanca O, Geary A, Suarez N, Benavent S, Gonzalez $\mathrm{M}$. Implementation of a diabetic retinopathy referral network. Peru Bull World Health Organ. 2018;96(10):674-81.

49. Wong TY, Sabanayagam C. Strategies to tackle the global burden of diabetic retinopathy: from epidemiology to artificial intelligence. Ophthalmologica. 2020;243(1):9-20.

50. Mukherjee AN, Watts P, Al-Madfai H, Manoj B, Roberts D. Impact of retinopathy of prematurity screening examination on cardiorespiratory indices: a comparison of indirect ophthalmoscopy and retcam imaging. Ophthalmology. 2006;113(9): 1547-52.

51. Patil J, Patil L, Parachuri N, et al. Smartphone based ROP (S-ROP) screening-opportunities and challenges. Eye (Lond). 2020. https://doi.org/10.1038/ s41433-020-0913-1.

52. Ataer-Cansizoglu E, Bolon-Canedo V, Campbell JP, et al. Computer-based image analysis for plus disease diagnosis in retinopathy of prematurity: performance of the "i-ROP" system and image features associated with expert diagnosis. Transl Vis Sci Technol. 2015;4(6):5. 